Submission ID: 42854

\title{
The Use of Seismic Cdp-3D for Indirect, Evidence for Fluid Migration of Hydrocarbons from the Bazhenov Formation in the Lower Cretaceous Deposits of Western Siberia
}

V.N. Borodkin * (Industrial University of Tyumen), A.R. Kurchikov (West Siberian Division of A.A. Trofimuk IPGGG of the Siberian Branch of the RAS), V.I. Samitova (West Siberian Division of A.A. Trofimuk IPGGG of the Siberian Branch of the RAS), A.S. Nedosekin (INGEOSERVIS), A.V. Lukashev (INGEOSERVIS), O.A. Smirnov (INGEOSERVIS)

\section{SUMMARY}

The same regularity in the change of physico-chemical properties of fluids and phase zoning of hydrocarbons in Jurassic and lower Cretaceous sediments.

On the basis of the organic hypothesis of petroleum formation and considering the Bazhenov shale as neferheperura thickness, in this case, the zone of anomalous sections of the Bazhenov formation are considered as a positive criterion for predicting oil and gas potential of Achimov strata due to the strengthening of processes of migration of hydrocarbons from the Bazhenov formation above the cut. Characteristic is the presence in the interval abnormal structure "zones fluid-dynamic unloading". Intraformational faults and "discharge zone" are clearly visible on the seismic attribute "Symmetry" along the OGB.

The presence of abnormally-high of potovyh pressure (abnormal high pressure) in the Achimov sequence is also one of the indicators of the migration of hydrocarbons from the Bazhenov formation, because oil deposits in the past all with AHP 
Использование сейсморазведки МОГТ-ЗД для косвенного подтверждения флюидомиграции углеводородов из баженовской свиты в нижнемеловые отложения Западной Сибири

В.Н. Бородкин (ТИУ)*, А.Р. Курчиков, В.И. Самитова (ЗСФ ИНГГ СО РАН), А.С. Недосекин, А.В. Лукашов, О.А. Смирнов (ООО «ИНГЕОСЕРВИС»)

В качестве полигона исследований взята Нерутинская впадина севера Западной Сибири, в пределах которой проводились сейсморазведочные работы МОВ ОГТ-ЗД. Перспективными в пределах впадин являются среднеюрский (пласты $Ю_{2-4}$ ), ачимовский (пласты Ач) и неокомский (пласты групп БУ, БП) нефтегазоносные комплексы (НГК), промышленная нефтеносность которых установлена в районе исследований.

Начальные суммарные ресурсы (НСР) углеводородов (УВ) в пределах впадины и прилегающих территорий в разрезе данных НГК составляют по нефти - 1071.9 млн т, газа 4863.8 млрд м $^{3}$ и конденсата - 835.8 млн т, при этом основная доля приходится на ачимовский НГК [1].

Исходя из изложенных ранее [2] принципов выделения сейсмофациальных комплексов (СФК) неокома, на основании выполненной сейсмогеологической корреляции по линии региональных сейсмопрофилей, откартированы границы площадного распространения клиноформных образований ачимовской толщи и изохронных прибрежно-мелководных резервуаров неокома [1]. В составе ачимовского НГК промышленная нефтегазоносность установлена в клиноформах БУ ${ }_{17-19} \mathrm{Aч}_{15}$, БУ ${ }_{16} \mathrm{Aч}_{13-14}, Б_{15} \mathrm{Aч}_{11-12}, Б_{13-14} А ч_{9-10}$, БУ$_{12} А ч_{7-8}$, БУ$_{10-}$ ${ }_{11} \mathrm{Aч}_{6}[3]$.

В границах впадины сейсморазведка МОГТ-ЗД выполнена на Западно-Юбилейной площади, в пределах которой установлена продуктивность клиноформ БУ ${ }_{13-14} \mathrm{Aч}_{9-10}$ и БУ ${ }_{12} \mathrm{~A}$ ч7-8 $_{2}$ ачимовской толщи, а также в верхнеюрских отложениях, связанных с верхневасюганской подсвитой (пласт $Ю_{1}$ ) оксфордского возраста. Привлечение результатов сейсмических атрибутов и выполненной инверсии позволило оконтурить границу распространения ловушки пласта $Ю_{1}$.

В приведенной нами ранее работе [4] при анализе физико-химических свойств углеводородов в залежах юрских и нижнемеловых отложений были установлены идентичные закономерности в изменении их параметров, которые в значительной степени определяются фазовой зональностью флюидных систем. Последняя схожа для залежей УВ данных осадочных образований. Это обстоятельство может быть объяснено с позиции генетической связи верхнеюрских отложений, отвечающих битуминозным аргиллитами баженовской свиты с высокими концентрациями планктонного органного вещества (ОВ) (Сорг. среднее - 5.1\%, максимальное в прослоях до 30-50\%) [5], с вышезалегающими ачимовскими отложениями, при частичной миграции УВ в клиноформные образования ачимовской толщи $[6,7]$ и изохронные прибрежно-мелководные неокомские отложения [8].

По-видимому, можно провести некоторую аналогию между представлениями Х. Хедберга [9] о процессах лавинной седиментации на подводных окраинах континентов и моделью лавинного осадконакопления отложений ачимовской толщи у подножий шельфовых склонов [10, 11]. Отличие между данными процессами заключается в том, что осадки ачимовской толщи не попадали в зону субдукции, а за счет турбидитной модели седиментации создавались условия для формирования аномальных разрезов баженовской свиты [10] (рис. 1).

Если исходить из позиции органической гипотезы нефтеобразования [12] и рассматривать баженовскую свиту как нефтегенерирующую толщу, обогащенную ОВ [5], то зоны аномальных разрезов следует рассматривать как положительный критерий прогноза нефтеносности ачимовской толщи [13] за счет усиления процессов миграции УВ из баженовской свиты в ачимовские образования $[6,7]$. Аномальный разрез баженовской свиты по керну установлен на соседней Юбилейной площади, в скв. 100, где наблюдаются оползневые текстуры с включениями битуминозных аргиллитов в отложения ачимовской толщи и внедрение песчаников толщи в литифицированные битуминозные аргиллиты баженовской свиты с элементами брекчирования (рис.2). Песчаники нефтенасыщенны как непосредственно в ачимовской толще, так и внутри баженовской свиты. 


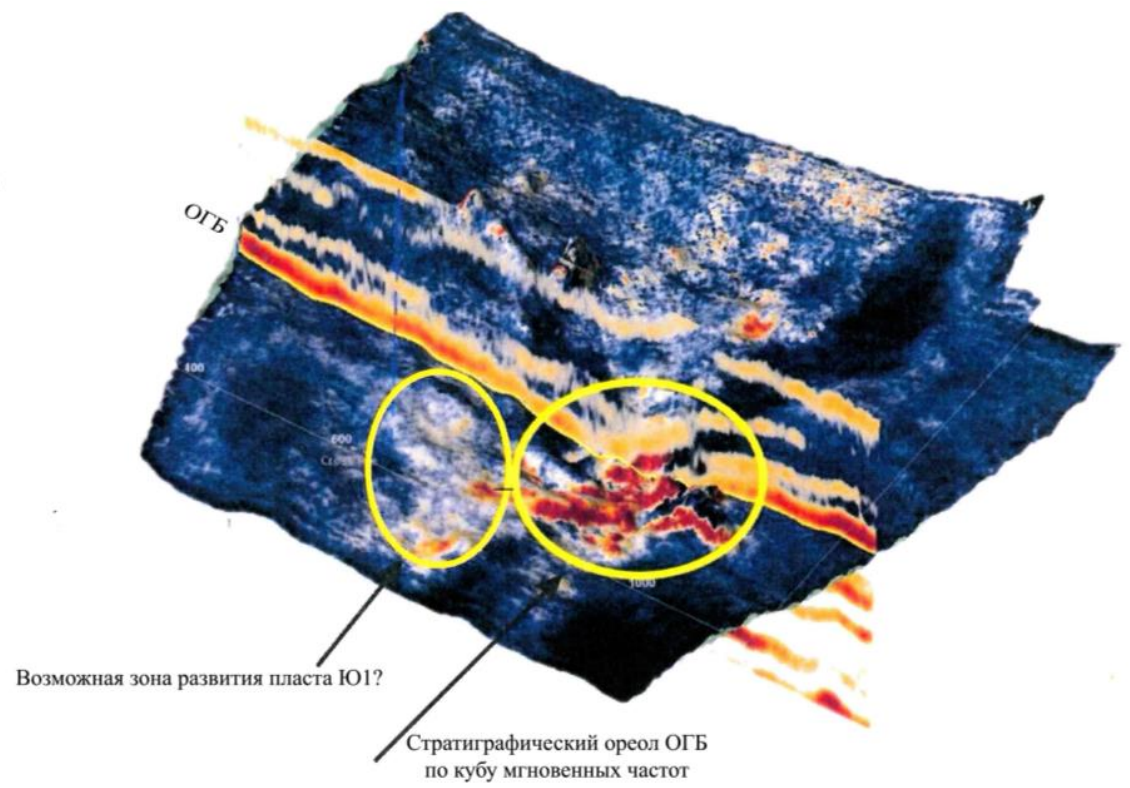

Рисунок 1 «Аномальный» разрез баженовской свитьл Западно-Юбилейной площуади

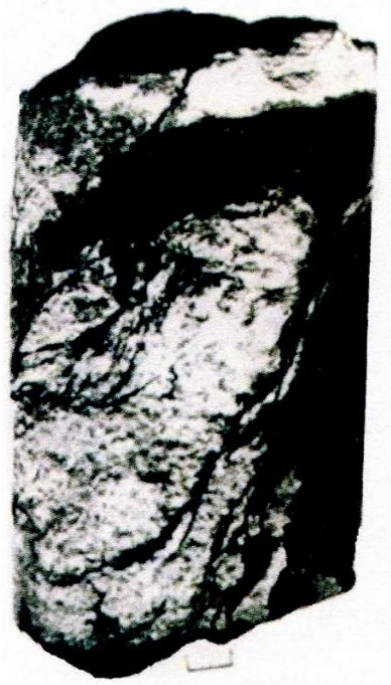

a
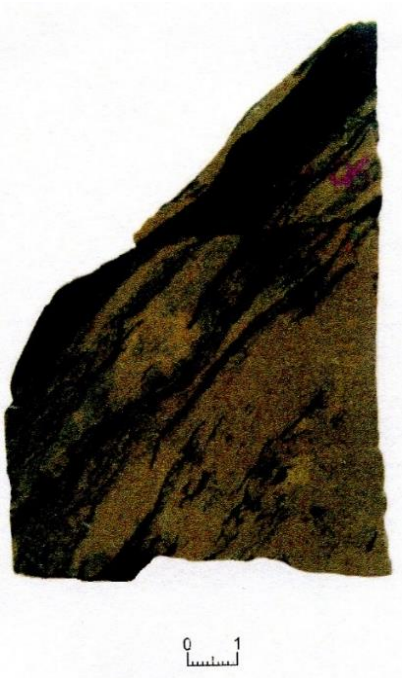

б

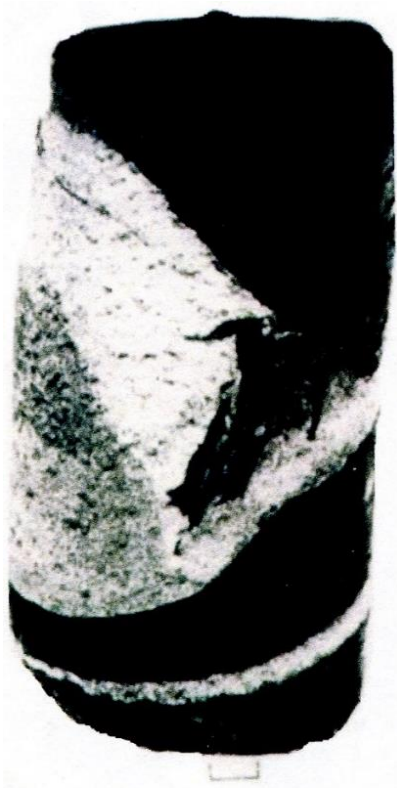

B

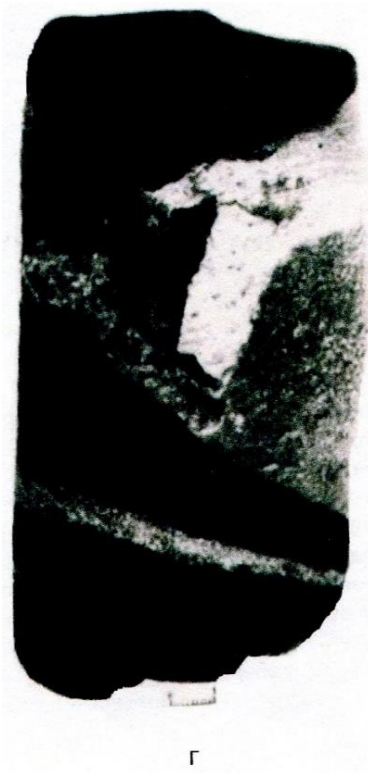

r

Рисунок 2 Оползневые (а, б) и брекчевидные текстуры (в, г), обусловленные внедрением песчаников ачимовской толщи в битуминозные аргиллиты баженовской свиты. Скважина 100 Юбилейной площади, интервал 3708-3729 м. Клиноформа БУ ${ }_{15} А ч_{11-12}$

На рис. 1 достаточно наглядно видна связь аномального разреза баженовской свиты с клиноформной моделью ачимовской толщи.

Следует отметить, что в связи с наличием аномальных разрезов баженовской свиты, со стратификацией линзовидного тела, связанного с пластом $Ю_{1}$ ? возникают определенные вопросы. В частности, если исходить из модели формирования аномальных разрезов баженовской свиты [10], то данные песчаники могут ответить фронтальной части аномального разреза (рис. 1), генетически связано с отложениями ачимовской толщи, возраст которой в данном районе по многочисленным находкам аммонитов $[10,11]$ валанжинский. Для выяснения данного вопроса необходимо из песчаников пласта Ю Юбилейной площади отобрать образцы на спорово-пыльцевой анализ. $\mathrm{B}$ случае 


\section{EAGE}

подтверждения валанжинского, а не оксфордского возраста песчаников вопрос о развитии пласта Ю $Ю_{1}$ в пределах Нерутинской впадины исключается.

Необходимо отметить наличие в интервале аномального строения баженовской свиты «зон флюидодинамической разгрузки». На рис. 3 представлена последовательность образования глубинных каналов миграции УВ («bubbie pressure», «pull up»). Первая стадия характеризуется зарождением очага избыточного давления, далее происходит разгрузка давления с образованием флюидодинамического канала (вторая стадия). В третьей стадии происходит разрушение сплошности с образованиями сейсмических «артефактов», которые выразительно проявляются на динамических и кинематических атрибутах.

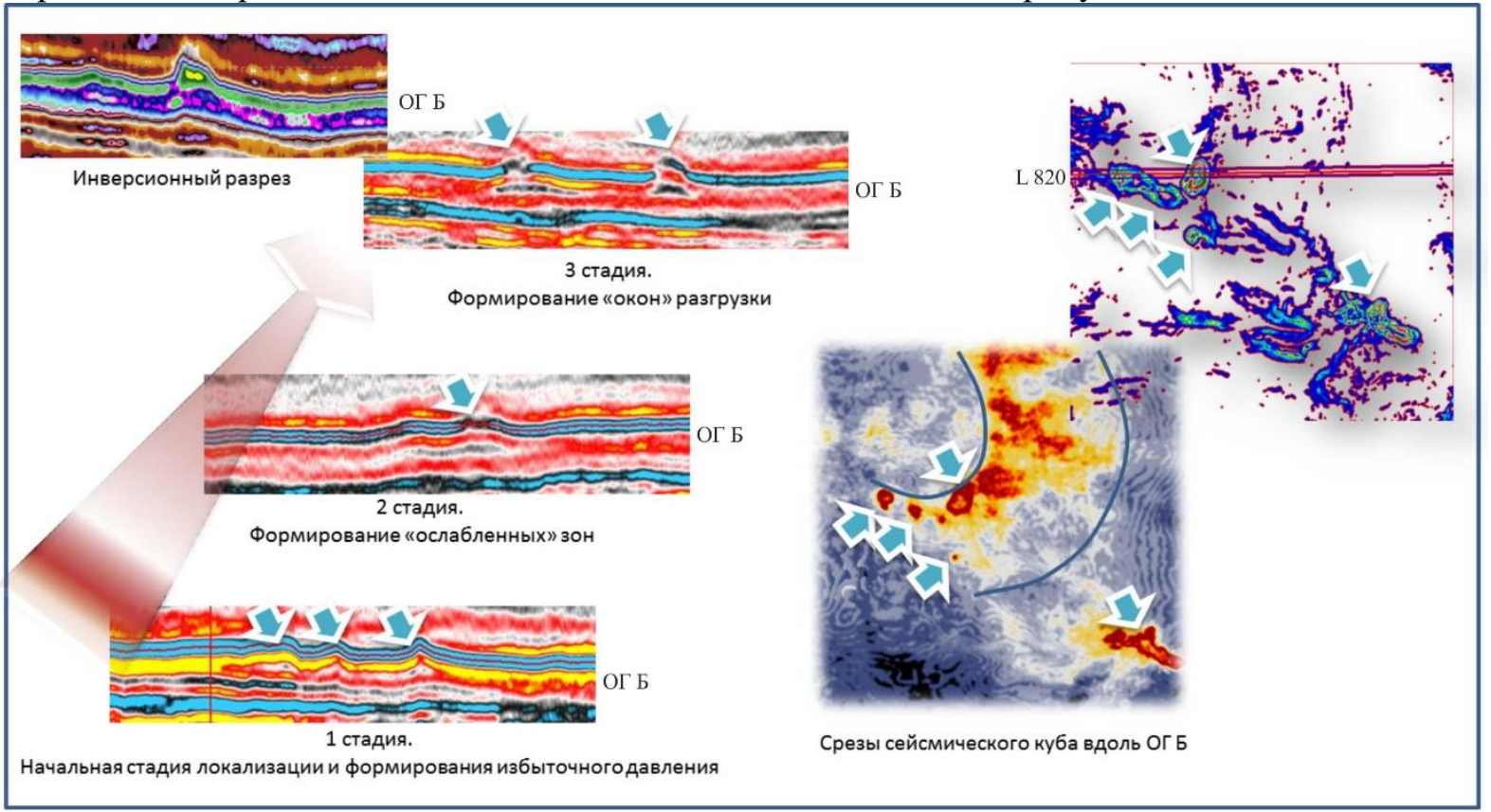

Рисунок 3 Последовательность образования глубинных каналов миграции УВ («bubble pressure», «Pull up»)

Внутриформационные разломы и «зоны разгрузки» хорошо видны на сейсмическом атрибуте «Symmetry» вдоль отражающего горизонта (ОГ) Б (рис. 4). Тектонические стрессы и локализация зон разгрузки связаны между собой.
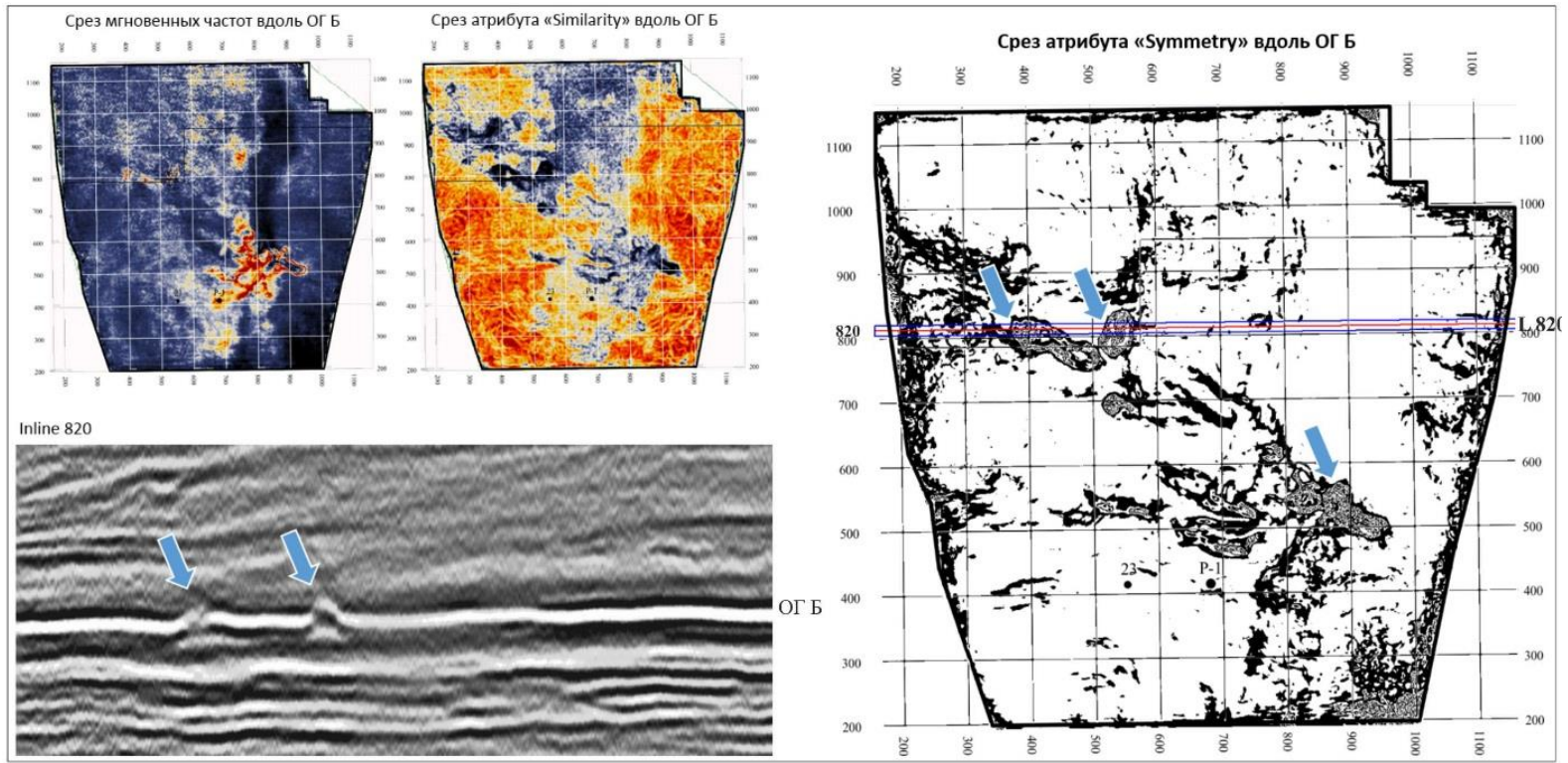

Рисунок 4 Глубинные каналь мигращии УВ (профиль L 820) 
Наличие аномально-высоких пластовых давлений (АВПД) в отложениях ачимовской толщи $[10,11]$ также является одним из показателей флюидомиграции углеводородов из баженовской свиты, поскольку для залежей нефти последней характерны АВПД (Салымское, В.-Салымское и др. месторождения).

Таким образом, материалы сейсморазведки 3Д косвенно подтверждают высказанную ранее А.Э. Конторовичем, С.Г. Неручевым и другими исследователями модель флюидомиграции углеводородов из баженовской свиты в вышезалегающие неокомские отложения Западной Сибири.

\section{Библиография}

1. Характеристика геологического строения и перспектива нефтеносности нижнемеловых отложений Нерутинской впадины и сопределтных территорий севера Западной Сибири / В.Н. Бородкин, А.Р. Курчиков, К.О. Забоев [и др.]// Геология, геофизика и разработка нефтяных и газовых месторождений. М.: ОАО «ВНИИОЭНГ», 2012, № 2, с. 12-22.

2. Бородкин В.Н., Курчиков А.Р. Материалы к уточнению стратиграфиеской схемы берриас-нижнеаптских отложений с учетом клиноформного строения разреза // Геология и геофизика. Новосибирск, 2010. Т. 51, № 12, с. 36-42.

3. Новые данные о перспективах нефтегазоносного ачимовского клиноформного комплекса в пределах юго-восточной части Нерутинской впадины / В.Н. Бородкин [и др.] // Горные ведомости, Тюмень, 2009, № 6, с. 4-9.

4. Закономерности изменения физико-химических свойств флюидных систем юрскомеловых отложений Западной Сибири с учетом их фазовой зональности и палеотектонических критериев / В.Н. Бородкин, А.Р. Курчиков, А.С. Недосекин [и др.] // Геология, геофизика и разработка нефтяных и газовых месторождений. М.: ОАО «ВНИИОЭНГ», 2016, № 6, с. 14-31.

5. Органическая геохимия мезозойских нефтегазоносных отложений Сибири. / А.Э. Конторович [и др.]//М: Недра, 1974, 192 с.

6. Углеводороды - биомаркеры в нефтях Среднего Приобья (Западная Сибирь / А.Э. Конторович [и др.]// Геология нефти и газа, 1991, № 10, с. 3-34.

7. Неручев С.Г. О возможности оценки прогнозных запасов нефти на генетической основе// Геология нефти и газа, 1964, № 7, с. 8-11.

8. Ершов С.В. Закономерности вертикального и латерального размещения залежей нефти в неокомских клиноформах Северного Приобья Западной Сибири// Геология, геофизика и разработка нефтяных и газовых месторождений. М.: ОАО «ВНИИОЭНГ», 2004, № 10, с. 12-19.

9. Hedberg H.D. Continental Margins from Viewpoint of the Petroienm Geologists. AAPG Bull., 1970, Vol., 54.

10. Геология и нефтегазоносность ачимовской толщи Западной Сибири/ А.А. Нежданов [и др.]//М. Изд-во Академии горных наук, 2000, 246 с.

11. Бородкин В.Н., Курчиков А.Р. Характеристики геологического строения и нефтегазоносности ачимовского нефтегазоносного комплекса Западной Сибири. Новосибирск, Изд-во СО РАН, 2015, 300 с.

12. Вассоевич Н.Б. Теория осадочно-миграционного происхождения нефти. М., Изд-во АН CCCP, 1967, c. 135-157.

13. Фациальная зональность верхнеюрского палеобассейна Западной Сибири/ А.Р. Курчиков, В.Н. Бородкин, А.С. Недосекин [и др.] // Геология, геофизика и разработка нефтяных и газовых месторождений. М.: ОАО «ВНИИОЭНГ», 2015, № 2, с. 4-11.

\section{References:}

1. Description of the geological structure and prospect of oil-bearing lower Cretaceous deposits Nuratinskiy depression and opredelnnyh territories of the North of Western Siberia / V. N. Borodkin, A. R. Kurchikov, K. O. Zaboev [and others]// Geology, Geophysics and development of oil and gas fields. M.: OAO "VNIIOENG", 2012, No. 2, pp. 12-22. 
2. Borodkin V. N., Kurchikov A. R. Materials to the refinement stratigraficheskoi scheme of the Berriasian-nizhneisetsky deposits subject to the clinoform section structure // Geology and Geophysics. Novosibirsk, 2010. Vol. 51, no. 12, pp. 36-42.

3. New data on hydrocarbon prospects Achim clinoform complex within the South-Eastern part Nuratinskiy basin / V. N. Borodkin [et al.] / / Mountain Vedomosti, Tyumen, 2009, No. 6, pp. 49.

4. The patterns of changes in physico-chemical properties of the fluid systems of the JurassicCretaceous deposits of Western Siberia taking into account their phase of zoning and paleotectonic criteria / V. N. Borodkin, A. R. Kurchikov, Nedosekin A. S. [and others] // Geology, Geophysics and development of oil and gas fields. M.: OAO "VNIIOENG", 2016, no. 6, pp. 14-31.

5. Organic Geochemistry of Mesozoic oil-gas deposits of Siberia. / A. E. Kontorovich [et al.] //M.: Nedra, 1974, 192 p.

6. Hydrocarbons - biomarkers in oils of the Middle Ob region (West Siberia / A. E. Kontorovich [and others]// Geology of oil and gas, 1991, no. 10, pp. 3-34.

7. Neruchev S. G. On the possibility of estimating prognostic reserves of oil on a genetic basis// Geology of oil and gas, 1964, No. 7, pp. 8-11.

8. Ershov S. V. Regularities of the vertical and lateral placement of oil deposits in clinoform Neocomian of the Northern Ob region of West Siberia// Geology, Geophysics and development of oil and gas fields. M.: OAO "VNIIOENG", 2004, № 10, pp. 12-19.

9. Hedberg H. D. Continental Margins from Viewpoint of the Petroienm Geologists. AAPG Bull., 1970, Vol. 54.

10. Geology and petroleum potential of the Achimov strata of Western Siberia/ A. A. Nezhdanov [et al.]//Moscow, publishing house of Academy of mining Sciences, 2000, $246 \mathrm{p}$.

11. Borodkin V. N., Kurchikov A. R. Characteristics of the geological structure and petroleum potential of the Achimov oil and gas complex of Western Siberia. Novosibirsk, Publishing house SB RAS, 2015, $300 \mathrm{p}$.

12. Vassoevich N. B. The theory of the sedimentary-migration origin of oil. M., Izd-vo an SSSR, 1967, pp. 135-157.

13. Facies zonation of the upper Jurassic basin of Western Siberia/ A. R. Kurchikov, V. N. Borodkin, A. S., Nedosekin [and others] // Geology, Geophysics and development of oil and gas fields. M.: OAO "VNIIOENG", 2015, № 2, p. 4-11. 